Ueber die Vcrarbeitung v. Oleum Cacao bei Pillen u. Suppositorien. 27

ist desshalb schwerlöslich und nicht „leichtlöslich in Spiritus. “*)

\title{
Ueber die Verarbeitung von Oleum Cacao bel Pillen und Suppositorien.
}

\author{
Von C. F. Schulze in Jena.
}

Da neuerdings Oleum Cacao bei Pillenmassen, die Phosphor in Substanz enthalten, mit Recht häufiger Anwendung findet und sich andere Vehikel in diesem Falle nicht mehr anwenden lassen, sei es mir gestattet, meine Erfahrungen uiber die Manipulationen bei der Bearbeitung dieser Masse hier mitzutheilen.

Der Phosphor wird zuerst in dem Cacaoöl gelöst und die Lösung zum Erkalten zugedeckt bei Seite gestellt. Nach dem Erkalten knetet man die Mischung in der warmen Hand eine Weile tüchtig durch und erhält so eine Pillenmasse, die an Plasticität Nichts zu wünschen übrig lässt.

Nicht nur zu diesem Zweck ist das Verfahren zu empfehlen, sondern lësst sich auch sehr gut bei der Bereitung solcher Suppositorien in Anwendung bringen, die mehr oder weniger pulverige Substanzen einschliessen sollen. In solchen Fällen agitirt man das geschmolzene Oel mit dem Pulver bis zum Erkalten, knetet das erkaltete Gemisch in der warmen Hand und formt schliesslich auf einem glatten Brettchen oder dergl. die übliche Kegelform.

*) Hier müsste doch, meine ich, nicht Alkohol und Spiritus in einem Satze gebraucht werden, da beide Worte wissenschaftlich sich einander gar nicht decken.

H. $L$. 